\title{
Application of Garch Models to Estimate and Predict Financial Volatility of Daily Stock Returns in Nigeria
}

\author{
Christopher N. Ekong, Kenneth U. Onye \\ Department of Economics, Faculty of Social Sciences, University of Uyo
}

\begin{abstract}
This paper estimates the optimal forecasting model of stock returns and the nature of stock returns volatility in Nigeria using daily All-Share stock data. The study unlike previous ones estimates six sets of symmetric and asymmetric GARCH-family models of stock returns volatility (three of which are augmented with trading volume) in three different set of error distributions: normal, student's $t$ and generalized error distribution (GED) with a view to selecting the model with best predictive power. Relying on root mean square error (RMSE) and Thiel's Inequality Coefficient, GARCH $(1,1)$ and augmented EGARCH $(1,1)$ in GED proved to possess the best forecasting capability as adjudged by the last 30 days out-of-sample forecast. Our finding also suggests the presence of leverage effect and decline in persistence parameter after incorporating trading volume. Overall, the result provides evidence of high probability of making negative return from investment in the Nigerian stock market over the sample period. The empirical merit of the model is, thus, its potential for applications in analysis of value at risk (VaR) of quoted stocks and, therefore, evaluation of risk premia that guide investors' choice of stock portfolio.
\end{abstract}

Keywords: Stock Returns, Forecasting, GARCH Model, Nigeria

\section{INTRODUCTION}

An established feature of stock returns is that they exhibit volatility clustering ${ }^{\mathbf{1}}$, i.e., periods of swing followed by periods of relative calm (Harvey and Chakravarty, 2008). In this regard, it was discovered that, for vast classes of models, the average size of volatility is not constant but changes with time in a manner that is predictable. Interestingly, the generalized auto-regressive conditional heteroscedasticity (GARCH) model introduced by Bollerslev (1986) and Taylor (1986) is among the oldest most widely used models for capturing volatility/risk, i.e., changing variances, in financial time series that exhibit time-varying volatility clustering ${ }^{2}$. Increasingly too, studies on the volatility of stock returns which have been dominated by time series models of conditional heteroscedasticity have tended to find strong supports for asymmetric ARCH/GARCH-type effect. In Nigeria, however, the contributions of error distributions seems to have been ignored while modeling stock market volatility even though past and recent studies have shown that the application of appropriate error distribution in volatility models enhances the efficiency of a model (see for e.g., Chang, 2010; Jiang, 2012).

More so, the ARCH/GARCH -type models do not provide a theoretical explanation of volatility or what, if any, the exact contribution of information ${ }^{3}$ flows are in the volatility-generating process. In

\footnotetext{
${ }^{1}$ Other stylized facts (features) of stock returns are heavy tails (conditional fat- tailed-ness), leverage (volatility asymmetry) and conditional skewness. Leverage means that negative returns tend to be associated with higher volatility than positive returns of the same magnitude. Fat tailed-ness means that the standardized conditional returns is more fat-tailed than the Gaussian (normal) returns while conditional skewness means that the standardized returns is not symmetric. For stock returns the skewness is typically negative which means that the probability of large negative return is greater than large positive returns- even after adjusting for the recent level of volatility.

${ }^{2}$ As Engle, Focardi and Fabozzi (2007:2) note, the discovery that it is possible to formalize and generalize this observation was a major breakthrough in econometrics.

${ }^{3}$ As we see in Engle, Farcodi and Fabozzi (2007) too, trade volume provide information that could help explain high stock return volatility using high frequency data.
} 
this regard, one of the early attempts ${ }^{4}$ to provide a theoretical explanation to volatility-generation process is the mixture of error distribution hypothesis (MDH) advanced by Clark (1973), and Epps and 'Epps (1976) (see e.g., Tauchen and Pitts, 1983; Lamoureux and Lastrapes, 1990for empirical evidences). According to $\mathrm{MDH}$, the variance of stock returns at a given interval is proportional to the rate of information arrival. As a result, volatility clustering could be a reflection of information arrival frequencies. All traders receive the new price signals fairly simultaneously and, therefore, the shift to a new equilibrium is immediate and there will be no intermediate partial equilibrium.

The specification of appropriate volatility model for capturing fluctuations in stock returns is of significant policy relevance to investors and policy makers alike. First, reliable volatility model of asset returns aids investors in their risk management decisions and portfolio adjustments. The search for reliable volatility model is also important because unfettered fluctuation in asset return could influence investment decision that can manifest in the real sector with adverse consequences for economic growth and development. Second, undue swings in asset returns could impose challenges to monetary policy formulation and consequently undermine the price stability objective of the monetary authority. For instance, increase in stock prices leads to higher interest rate (see Fischer 1981)that could generate inflationary spree in the economy (see Spiro, 1990).As De Gruwe (2008) argues, asset price inflation inevitably lead to crashes. In this regard, stabilization policy is needed since those policies that stabilize asset price can also stabilize inflation and output. Therefore, the determination of the nature of stock returns volatility and its optimal forecasting model makes a crucial precondition for the Central Bank's intervention in the Nigerian Stock Market.

The paper has two-fold objectives, namely to: (i) examine the nature of volatility/risk of stock returns in Nigeria and (ii) determine the optimal forecasting model for Nigerian stocks and their predictability.

Similar study has been done by Chiang (2010) who analyzed the Chinese stock exchange, Jiang (2012) who analyzed the New York stock exchange and Tian and Guo (2006) who analyzed the Shangai and Shenzhen exchanges of the Chinese Stock market. We apply the commonly used GARCH-family models on Gaussian (normal), student's $t$ and generalized error distribution with a view to selecting the best forecasting volatility model with the appropriate error distribution for the Nigeria stock market over the sample period.

The rest of the paper is organized as follows. Section 2 deals with the theoretical and empirical literature, and the analytical framework of GARCH- family models adopted for the study while the methodology and data is presented in section 3. Section 4 discusses the results with applications and section 5 concludes the paper.

\section{LiteratURE REVIEW}

This sub-section, as has been noted, deals with the review of relevant theoretical and empirical literature on modeling the volatility of stock returns. The analytical scheme - i.e., the specific technique chosen to investigate stock returns volatility - namely the GARCH-family models, adopted for the study is also discussed.

\subsection{Theoretical Literature}

The use of auto-regressive conditional heterosceadsticity models for analyzing volatility of asset returns was due to the pioneering work of Engle (1982) where the conditional variance of a disturbance term was made a function of linear combination of squared residuals in the recent past. Progressively, the potential of the ARCH model spurred a number of other researches that resulted in the development of several other ARCH-type models. As we see in Rydberg (2000), the fact that large lag values are required in the ARCH models implies that many parameters are needed which sometimes lead to over-parametization.

To achieve a parsimonious model, therefore, Bolerslev (1986) and Taylor (1986) independently proposed the extension of ARCH model with an Autoregressive Moving Average (ARMA) formulation. This model, which is popularly called the Generalized ARCH model (GARCH), models

\footnotetext{
${ }^{4}$ Alternative explanation of volatility clustering include the existence of autocorrelation in the news arrival process of Diebold and Nerlove (1989); Sequential Information arrival hypothesis of Copeland (1976); and market microstructure effects of Bollerslev and Domowitz (1991).
} 
conditional variance as a function of its lagged values as well as squared lagged values of the disturbance term. Although, the GARCH model has proved very useful in capturing symmetric effect of volatility, it has certain limitations. For instance, it assumes that positive and negative error terms have a symmetric effect on volatility, i.e., good and bad news have the same size of effect on volatility in the model. In practice, this assumption is frequently violated by stock returns, in particular, in that volatility tends to increase more after bad news than after good news (especially in non-crisis periods), the so-called leverage effect (first proposed by Black, 1976). Technically, this assumption implies that the estimated parameters in the GARCH model are restricted to a positive value, the so-called non-negativity parameter restriction. In other words, a major limitation of the GARCH model is that in reality the non-negativity constraint imposed on the parameter of the GARCH model is frequently violated ${ }^{5}$.

To overcome these constraints, the asymmetric GARCH-family models (which are extensions of the original GARCH model) have been proposed. These include the Exponential GARCH model (EGARCH) proposed by Nelson (1991), the Power GARCH (PGARCH) proposed by Ding, Granger and Engle (1993), the Threshold GARCH (TGARCH) proposed by Zakoian (1994), and the Beta-tGARCH family models proposed by Harvey and Chakravarty, 2008) and elaborated in the ensuing literature by Harvey and Sucarrat (2012).The central idea behind this asymmetric GARCH-family model is the leverage effect, i.e., the fact that in reality good and bad news of the same magnitude have differential effects on the volatility (conditional variance) of stock returns.

The Exponential GARCH model which captures the asymmetric properties of stock returns volatility was proposed to address three principal deficiencies of GARCH model. These are: (i) restriction of the estimable parameters to a positive value to ensure positive effect on conditional variance; (ii) absence of asymmetric response of volatility to shocks (e.g. from lagged residuals, variances and/or trade volumes), i.e., absence of asymmetric term in GARCH model; (iii) difficulty in measuring volatility persistence in a strongly stationary series. The use of log-conditional variance in the EGARCH model rather than conditional variance (as is the case in normal GARCH model) implies that the leverage effect (asymmetric response of volatility) is exponential and not quadratic. In other words, the specification of volatility (conditional variance) in terms of its logarithmic transformation implies that the parameters are no longer restricted to positive value. That is, the more realistic case wherein volatility response differentially to good news (positive shock) and bad news (negative shock) of the same magnitude is captured. This is a key advantage of EGARCH model over the symmetric GARCH model.

In Ding, Granger and Engle (1993), the standard deviation of GARCH model initially proposed by Bollerslev (1986), Taylor (1986) and Schwert (1989) is further generalized in such a way that the conditional standard deviation is raised to a power, $d$ (positive exponent). The d-power conditional standard deviation is modeled as a function of lagged conditional standard deviation and lagged absolute innovations raised to the same power (d). The resultant model is called the power GARCH. The expression becomes a standard GARCH model when the positive exponent is set at two. Interestingly, the provision for the switching of the power increases the flexibility of the model.

Similarly, in Zakoian (1994), the TGARCH model is specified by allowing the conditional standard deviation in the standard GARCH to depend on the sign of lagged innovations. This specification does not restrict parameter to a positive value. As has been said, one may note that parameter restriction to positive value is meant to guarantee the positivity of volatility (conditional variance). Nonetheless, to ensure stationarity of the TGARCH model, the parameters have to be restricted and the choice of error distribution should account for the stationarity. The TGARCH model is closely related to the GJR-GARCH model developed by Glosten et al. (1993).

It is insightful to note that in response to the criticism concerning the a-theoretical nature of GARCHfamily models, the standard asymmetric GARCH-family models are now augmented with trading volume. In this regard, the pioneering work of Lamoureux and Lastrapes (1990) have found evidence

\footnotetext{
${ }^{5}$ In this regard, the asymmetric coefficients of asymmetric GARCH-family model are allowed to assume positive or negative values.
} 
that the inclusion of trading volumes in GARCH models of return results in a decrease of the estimated volatility persistence or even causes it to disappear. Few studies have, however, found persistence in volatility even after incorporating trading volume as an information variable (see e.g. Najand and Yung, 1991; Chen et al, 2001). This show that the effect of trading volume on stock returns volatility is still an empirical issue. This study, therefore, finds it necessary to test the effect of trade volume in explaining stock returns volatility in the context of the Nigerian stock market.

In term of choice of appropriate error distribution, economics and finance literature is also not unequivocal over appropriate choice of error distribution (normal, student-t or generalized error distribution) for robust modeling of stock returns. Since stock returns are characterized by certain stylized facts such as volatility clustering, leverage effect (asymmetric response of volatility to positive and negative shocks of the same magnitude) and are frequently fat-tailed, the traditional assumption of normality in volatility modeling of stock returns could lead to less than robust regression estimates. As we see in Mandelbrot (1963) and Fama (1965), it is deduced that daily stock returns are non-Gaussian and tend to have leptokurtic and fat-failed distribution. For this reason, Bollerslev (1986) relaxed the traditional normality assumption to accommodate time varying volatility by assuming that the error is student-t distributed. Similarly, Malmsten and Terasvirta (2004) argue that first order EGARCH model in normal error is not sufficiently flexible enough for capturing kurtosis and autocorrelation in stock returns. They, therefore, suggested that the standard GARCH model could be improved by replacing the normal error distribution with more fat-tailed error distribution since increasing the kurtosis of the error distribution will help standard GARCH model capture kurtosis in stock returns series.

In this same line of thinking, Nelson (1991) recommended the use of EGARCH model with generalized error distribution (GED) based on, at least, two of its desirable properties. First, a student$\mathrm{t}$ error distribution may imply infinite unconditional variance for the errors; hence, the GED which accommodates more fat-tails than normal error distribution could help to increase the kurtosis and reduce the autocorrelation of squared observation. Second, the EGARCH model is stationary if the innovations have a generalized error distribution (GED).This study, therefore, estimates first order symmetric and asymmetric GARCH-family models, each, in Normal, Student's-t and generalized error distributions (GED) with a view to determining the volatility model with best predictive power in the most appropriate error distribution. This is important not only for proper forecasting of stock return in Nigeria that guide investor's portfolio choice, it is also necessary for accurate assessment of value at risk (VaR). Importantly, the determination of optimal forecasting model of stock returns makes a crucial pre-condition for the Central Bank's intervention in the stock exchange market.

\subsection{Review of Empirical Literature}

Following the seminal work of Engle (1982) on volatility modeling, several other works have been done. Yet, certain theoretical/empirical issue, such as the effect of error distribution assumption on the conditional variance (volatility)and forecasting performance of GARCH family models, is scarce and unresolved (see Franses and McAleer, 2002;Anders, 2006). Some of the works on volatility modeling estimate a particular GARCH model with one or two error distributions, while some apply a particular error distribution to few ARCH family models to either: (i) establish the best forecasting model for conditional variance; (ii) determine the best fitted volatility model or; (iii) confirm the ability of a model to capture stylized facts inherent in high frequency financial time series. As has been noted, the contribution of trade volume (as a surrogate for information arrival to explain stock return volatility) and error distribution assumption on the forecasting performance of returns volatility is very scanty (minimal). As Atoi (2014) notes, available literature tend to capture the asymmetric properties of financial data without recourse to error distribution.

Jayasuriya (2002) examines the effect of stock market liberalization on stock returns volatility in Nigeria and fourteen other emerging market data, from December 1984 to March 2000 to estimate symmetric GARCH model. The study found that positive (negative) changes in prices have been followed by negative (positive) changes in volatility. The Nigeria portion of the result indicates more of business cycle behavior of stock return rather than volatility clustering. In studying volatility behavior of stock returns for emerging markets, Ogum et al (2005) apply the Nigerian and Kenya stock data on EGARCH model. The finding differed from that of Jayasuriya (2002). Although volatility persistence was found in both markets; volatility responds more to negative shocks in the Nigeria market and the reverse is the case for Kenya market. 
Okpara and Nwezeaku (2009) randomly selected forty one companies from the Nigerian stock Exchange to examine the impact of beta and idiosyncratic risk on returns using data from 1996 to 2005 . By relying on EGARCH $(1,3)$ model, the result shows less volatility persistence and indicates the presence of leverage effect in the Nigerian stock exchange, implying that bad news (negative shock) drives volatility more than good news (positive shock) of equal magnitude. Dallah and Ade (2010) investigated the volatility of daily stock returns of Nigerian insurance stocks using daily data from twenty six insurance companies covering a period of December 15, 2000 to June 9, 2008 as control data set and from June 102008 to September 9, 2008 as out-of-sample dataset. The results of ARCH (1), GARCH $(1,1)$, TARCH $(1,1)$ and EGARCH $(1,1)$ indicate that EGARCH is more suitable in modeling stock returns as it outperforms the other models in the model-fit evaluation (using Schwarz and Aikike information ) and out-of-sample forecast (using RMSE and Thiel's Inequality Coefficient).

A too I (2014) examines a set of first order symmetric and asymmetric ARCH family model using daily Nigerian All Shares Index (ASI) from June 2, 2008 to February 112013 under alternative error distributions (normal, student-t, and generalized error distribution). The result shows that PGARCH $(1,1,1)$ in student-t error distribution has the best predictive power based on root mean square error (RMSE) and Theil's inequality coefficient (TIC). The findings also shows the presence of leverage effect and recommends that empirical works should consider alternative error distributions so as to guarantee robust volatility forecasting model for sound policy decision and proper investment portfolio choice.

Chang (2010) analyzes the effect of the economic and financial crisis on Chinese stock return volatility using daily data from 2000 to 2007 as the pre-crisis period and 2007 to 2010 as the duringcrisis period. The findings show that the EGARCH model fits the data better than the GARCH model in modeling the volatility of Chinese stock returns. The result also indicates that volatility is more persistent during crisis period than in pre-crisis period.

Dallah and Ade (2010) examined the volatility of daily stock returns of the Nigerian insurance stocks using daily data from twenty six insurance companies. The period December 15, 2000 to June 9, 2008 was considered as the training data set and from June 10, 2008 to September 9, 2008 as out-of-sample data set. The result of ARCH (1), GARCH $(1,1), \operatorname{TGARCH}(1,1)$ and $\operatorname{EGARCH}(1,1)$ indicates that EGARCH $(1,1)$ is more suitable in modeling stock price returns as it outperforms the other models in model evaluation and out-of-sample forecast.

An evaluation of the state of literature on GARCH family models shows that alternative error distributions (normal or Gaussian, student's $t$ and generalized error distribution) have so far been ignored in modeling the volatility of stock returns in Nigeria. This study adds value to existing studies in this area by modeling stock returns volatility in three alternative error distributions with a view to selecting an optimal forecasting model for Nigeria. Further, in response to criticism concerning the a theoretical nature of volatility models, this study includes trading volume as an information variable (as suggested by Lamoureux and Lastrapes, 1990; Najand and Youn, 1991; Chen at al, 2001) to explain volatility of stock return in Nigeria.

\subsection{Analytical Framework of ARCH/GARCH Family Models}

\section{The ARCH Model (Engel 1982 Model)}

Every ARCH or GARCH family model requires two distinct specifications: the mean and variance equations. According to Engel, conditional heteroscedasticity in a stock return (SRET) - denoted byyt - can be modeled using ARCH model expressing the mean equation in the form:

$$
y_{t}=a_{0}+a_{1} y_{t-1}+\cdots+a_{q} y_{t-q}+\epsilon_{t}=a_{0}+\sum_{i=1}^{q} a_{i} y_{t-i}+\epsilon_{t}
$$

Equation 1 is a ' $q$ ' order autoregressive model. The mean equation is the same for all ARCH/GARCH family models.

$\varepsilon t=\sigma 1 \mathrm{v} 1$, where $\mathrm{v} 1=$ i. i. d. $\mathrm{N}(0,1)$, i.e., the residual $(\varepsilon t)$ is independent and identically distributed with a mean of zero and unit variance. The conditional variance (volatility) is modeled with the use of ARCH model by specifying the series $\sigma_{t}^{2}$ thus: 
$\sigma_{t}^{2}=\alpha_{0}+\alpha_{1} \epsilon_{t-1}^{2}+\cdots+\alpha_{q} \epsilon_{t-q}^{2}=\alpha_{0}+\sum_{i=1}^{q} \alpha_{i} \epsilon_{t-i}^{2}$

Where $\alpha_{0}>0$ and $\alpha_{i} \geq 0, i>0$.

An ARCH (q) model can be estimated using ordinary least square (OLS).

To test for the presence of ARCH effect (i.e., the presence of ARCH component), we need to check if

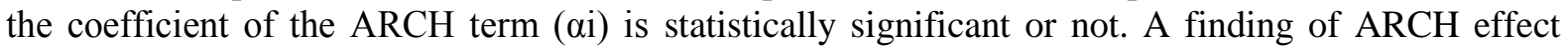
justifies the use of GARCH family models. We employ the Langrange Multiplier test procedure proposed by Engle (1982) or the ARCH LM test. This procedure is as follows:

First, we estimate the best fitting autoregressive model ARCH (q),

and obtain the squares of the error $\hat{\epsilon}^{2}$ and then regress them on a constant $(\alpha 0)$ and q lagged values of the residual as follows:

$\hat{\epsilon}_{t}^{2}=\hat{\alpha}_{0}+\sum_{i=1}^{q} \hat{\alpha}_{i} \hat{\epsilon}_{t-i}^{2}$

where $\mathrm{q}$ is the lag order, i.e., length of ARCH lags.

The hypothesis of ARCH effect is stated as follows:

Ho: $\alpha \mathrm{i}=0$ for all $\mathrm{i}=1 \ldots \mathrm{q}$.

H1: $\alpha \mathrm{i}$ is not equal to 0

The decision rule for test of ARCH effect is as follows:

If probability value is less than 5\%, we reject $\mathrm{H} 0$ (which say that there is no $\mathrm{ARCH}$ effect) and accept $\mathrm{H} 1$. In other words, we conclude that there is an ARCH effect. As has been noted, the mean equation is the same for all ARCH/GRACH family models

\subsection{GARCH (p, q) Model - Bollerslev (1986) and Taylor (1986) Model}

If an autoregressive moving average model (ARMA model) is found for the error variance $(\sigma \mathrm{t} 2)$, the model is a generalized autoregressive conditional heteroskedasticity (GARCH) model. The general specification of GARCH $(p, q)$ is as follows:

$\sigma_{t}^{2}=\alpha_{0}+\alpha_{1} \epsilon_{t-1}^{2}+\cdots+\alpha_{q} \epsilon_{t-q}^{2}+\beta_{1} \sigma_{t-1}^{2}+\cdots+\beta_{p} \sigma_{t-p}^{2}=\alpha_{0}+\sum_{i=1}^{q} \alpha_{i} \epsilon_{t-i}^{2}+\sum_{i=1}^{p} \beta_{i} \sigma_{t-i}^{2}$

Where $\alpha \mathrm{i}=$ coefficients of the ARCH component; and $\beta \mathrm{i}=$ coefficient of the GARCH component.

The three parameter $(\alpha 0$, $\alpha \mathrm{i}$ and $\beta \mathrm{i})$ are restricted to be positive (assumed to be non-negative) and $\alpha \mathrm{i}+$ $\beta \mathrm{i}<1$ to achieve stationarity

The test for the present of GARCH effect is established in two steps:

First, we estimate the best fitting AR(q) model which is the AR (q) model with a lag order that gives the lowest Aikike and Swartz information and highest log-likelihood ratio.

Compute and plot the autocorrelations of $\hat{\epsilon}^{2}$ by

$\rho=\frac{\sum_{t=i+1}^{T}\left(\hat{\epsilon}_{t}^{2}-\hat{\sigma}_{t}^{2}\right)\left(\hat{\epsilon}_{t-1}^{2}-\hat{\sigma}_{t-1}^{2}\right)}{\sum_{t=1}^{T}\left(\hat{\epsilon}_{t}^{2}-\hat{\sigma}_{t}^{2}\right)^{2}}$

The Exponential GARCH Model, EGARCH (Nelson, 1991)

The exponential generalized autoregressive conditional heteroskedasticity (EGARCH) model by Nelson (1991) is another version of the GARCH $(p, q)$ model. The modification is that the lagged squared autoregressive component ( $\epsilon 2 \mathrm{t}-\mathrm{i})$ appearing in the standard GARCH model is replaced with a standard normal variable which may also come from a generalized error distribution (GED). Thus, the conditional variance of EGARCH $(\mathrm{p}, \mathrm{q})$ model is specified generally as: 


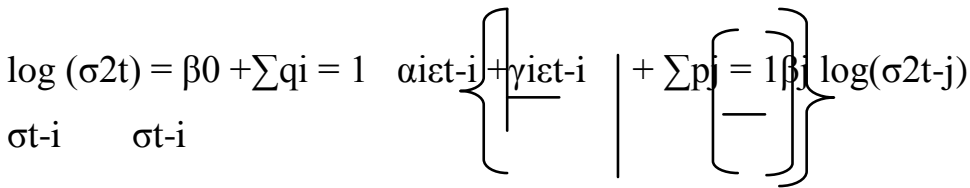

Where $\alpha \mathrm{i}, \gamma \mathrm{i}, \beta \mathrm{j}$ are the coefficients of the $\mathrm{ARCH}$, asymmetric and GARCH terms, respectively.

$\varepsilon t-1>0$ and $\varepsilon t-1<0$ implies good news and bad news respectively. Their total effects are $(1+\gamma \mathrm{i})|\varepsilon t-1|$ and $(1-\gamma \mathrm{i})|\varepsilon t-1|$, respectively.

When $\gamma \mathrm{i}<0$ (statistically), the expectation is that bad news would have higher impact on volatility. The EGARCH model achieves covariance stationarity when $\sum \mathrm{pj}=1 \beta \mathrm{j}<1$.

Failing to accept the null hypothesis (H0) that $\gamma \mathrm{i}=0$ (i.e., the acceptance of the $\mathrm{H} 1$ that $\gamma \mathrm{i}<0$ ) shows the presence of leverage effect, that is bad news have stronger effect than good news on the volatility of stock index return.

\subsection{Threshold GARCH (TGARCH) Model (Zakoian, 1994)}

The TGARCH model is similar to GJR-GARCH in that it also introduces asymmetry into the model. The generalized specification of the conditional variance using TGARCH $(\mathrm{p}, \mathrm{q})$ is stated as follows:

$\sigma 2 \mathrm{t}=\beta 0+\sum \mathrm{qi}=\mathrm{i \alpha ii} \varepsilon 2 \mathrm{t}-\mathrm{i}+\sum \mathrm{qi}=1 \gamma \mathrm{ilt}-\mathrm{i} \varepsilon 2 \mathrm{t}-\mathrm{i}+\sum \mathrm{pj}=1 \beta \mathrm{j} \sigma 2 \mathrm{t}-\mathrm{j}$

Where It- $\mathrm{i}=1$ if $\epsilon 2 \mathrm{t}<0$ and 0 otherwise. In other words, It-I is a binary number which assume a value of 1 if there is bad news, $\varepsilon 2 \mathrm{t}<0$ (negative shock) and zero if there is good news (positive shock).

In the TGARCH model, bad news implies that $\epsilon 2 \mathrm{t}-\mathrm{i}<0$ and good news implies that $\varepsilon 2 \mathrm{t}-\mathrm{i}>0$ and these two shocks of equal magnitude have differential effects on the conditional variance. Good news has an impact of $\alpha \mathrm{i}$ and bad news has an impact of $\alpha \mathrm{i}+\gamma \mathrm{i}$. Bad news increases volatility when $\gamma \mathrm{i}>0$, which implies the existence of leverage effect in the $i$-th order and when $\gamma \mathrm{i} \neq 0$ the news impact is asymmetric.

\subsection{Augmented Asymmetric GARCH- Family Models}

As has been noted, the occurrence of a time dependent conditional heteroscedasticity could be due to an increased volume of trading and/or variability of prices following the arrival of new information into the market. Trading volume is used as a measure of information flow. Lamoureux and Lastrapes (1990) empirically verified that the use of trading volume (as an additional variable in the conditional variance equation) leads to a significant decrease in volatility persistence $(\alpha+\beta)$ or, sometimes, a persistent parameter that is close to zero. Nonetheless, Lamoureux and Lastrapes (1990) also recognized that the use of contemporaneous trading volumes to explain volatility raises the issue of simultaneity bias, in that trading volume will not be a strict exogenous variable to stock returns. To solve this problem, Najand and Yung (1991) use lagged trading volume in their volatility equation. Recently, Tian and Guo (2006) using raw lagged volume and natural log of lagged volume as an explanatory variable to augment the GARCH-family models found that the log of lagged volume achieve better results in terms of removing GARCH and ARCH effects.

In this regard, this study augments the symmetric and asymmetric GARCH family models (GARCH, EGARCH and TGARCH) employed in the study using log of lagged trading volume.

All the three estimable models for the study (GARCH, EGARCH, TGARCH) and their augmented versions (augmented GARCH, augmented EGARCH and augmented TGARCH) are estimated in three alternative error distributions (normal, student-t and generalized error distribution). This gives rise to eighteen vitality models (see result in Table 1).

\subsection{Error Distribution and Likelihood Functions}

To check the contribution of alternative error distribution to a robust modeling of the stock returns series, all estimable models (GARCH, EGARCH, TGARCH and their augmented versions) are estimated, each, in Gaussian (normal), student-t and generalized error distribution. The output from the alternative error distribution is evaluated on the basis of minimal Swartz information criteria, maximum log likelihood ratio and minimal volatility persistence, among others. The likelihood function, $\mathrm{L}(\theta \mathrm{t})$, is given as 


$$
\begin{array}{r}
L\left(\theta_{\mathrm{t}}\right)=-1 / 2 \Sigma_{\mathrm{t}-1}^{\mathrm{T}}\left(\ln 2 \pi+\ln \sigma_{\mathrm{t}}^{2}+\varepsilon_{\mathrm{t}}^{2}\right) \\
\sigma_{\mathrm{t}}
\end{array}
$$

The $\log$ variance (volatility), i.e., $\log \sigma_{t}^{2}$, is specified for each of GARCH family models. Our assumption that the estimable models may follow alternative error distribution (GED or student-t) other than the usual Gaussian (normal) assumption tends to account for kurtosis in high frequency return series, which are not adequately captured with normality assumption. As in equation 8, the volatility models are estimated with GED by maximizing the likelihood function as follows:

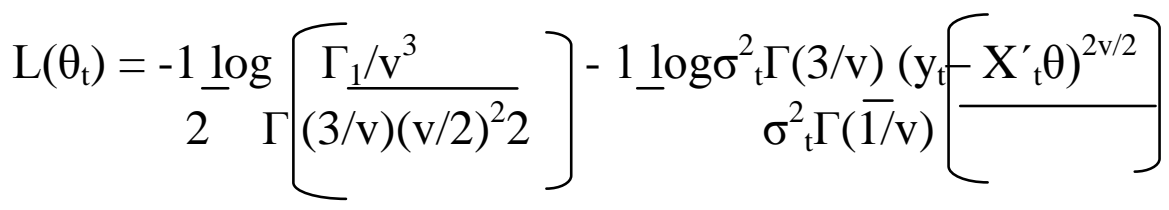

Where $\mathrm{v}>0 . \mathrm{V}$ is the shape parameter which accounts for the skewness of returns. The larger the value of $v$ the greater the weight of the tail. Generalized error distribution (GED) reverts to normal distribution if $\mathrm{v}=0$.

In the case of student-t distribution, the volatility models considered are estimated to maximize the likelihood function of student's t-distribution as follows:

$$
\left.\left.\mathrm{L}(\theta)_{\mathrm{t}}=-\begin{array}{c}
1 \log \mathrm{I}\left[\mathrm{I}(\mathrm{r}) \Gamma \mathrm{r} / 2^{2}\right. \\
2 \Gamma((\mathrm{t}+1) / 2)^{2} 2
\end{array}\right]-\frac{1 \log \sigma_{\mathrm{t}}^{2}}{2} \stackrel{(\mathrm{r}+1) \log 1\left[+\mathrm{yt}^{\prime} \mathrm{x}_{\mathrm{t}}^{\prime} \theta\right)^{2}}{\sigma_{\mathrm{t}}^{2}(\mathrm{r}-2)}\right]
$$

Where $r>2$; Here, $r$ is the degree of freedom and controls the tail behavior. The econometric specification of equation 8, 9 and 10is adopted from E Views 7.0 manual (also see Graham, 2005 and Eric, 2008 for further expositions on generalized error distribution).

\section{Methodology ANd Data}

This sub-section deals with the specification of our estimable GARCH family models, data source and transformation and model selection/forecasting evaluation.

\subsection{Estimable GARCH-Family Models}

$$
\begin{aligned}
& \sigma_{\mathrm{t}}^{2}=\alpha_{0}+\sum_{k=1}^{q} \alpha_{1} \varepsilon_{\mathrm{t}-1}^{2}+\quad \sum_{k=j}^{q} \quad \beta_{\mathrm{j}} \sigma_{\mathrm{t}-1}^{2} \\
& \log \left(\sigma_{\mathrm{t}}^{2}\right)=\beta_{0}+\sum_{\mathrm{i}=1}^{\mathrm{q}} \quad \alpha_{1} \varepsilon_{\mathrm{t}-\left.\right|_{\sigma_{\mathrm{t}-1}}}+\left.\gamma_{\mathrm{t}-1}\right|_{\mathrm{t}-1}[+] \sum_{\mathrm{j}=1}^{\mathrm{p}} \beta_{\mathrm{j}} \log \left(\sigma_{\mathrm{t}-1}^{2}\right) \\
& \sigma^{2} \mathrm{t}=\beta_{0}+\alpha_{1} \varepsilon_{\mathrm{t}-1}^{2}+\gamma_{1} \mathrm{I}_{\mathrm{t}-1} \varepsilon_{\mathrm{t}-1}^{2}+\beta_{1} \sigma_{\mathrm{t}-1}^{2}
\end{aligned}
$$

Equation 11, 12 and 13 are the estimable $\operatorname{GARCH}(1,1), \operatorname{EGARCH}(1,1)$ and $\operatorname{TGARCH}(1,1)$ models, respectively. The respective augmented GARCH $(1,1)$, EGARCH $(1,1)$ and TGARCH $(1,1)$ models are specified as equations 14,15 and 16 , thus;

$$
\begin{aligned}
& \sigma_{\mathrm{t}}^{2}=\alpha_{0}+\quad \sum_{k=1}^{q} \quad \alpha_{1} \varepsilon_{\mathrm{t}-1}^{2}+\quad \sum_{k=j}^{q} \quad \beta_{\mathrm{j}} \sigma_{\mathrm{t}-1}^{2}+\psi \log \text { Volume }_{\mathrm{t}-1}
\end{aligned}
$$

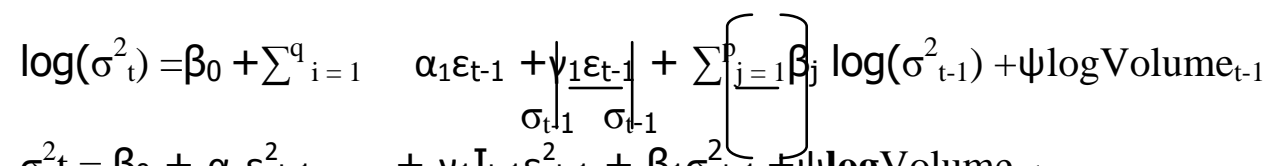

$$
\begin{aligned}
& \sigma^{2} \mathrm{t}=\beta_{0}+\alpha_{1} \varepsilon_{\mathrm{t}-1}^{2} \quad+\gamma_{1} \mathrm{I}_{\mathrm{t}-1} \varepsilon_{\mathrm{t}-1}^{2}+\beta_{1} \sigma_{\mathrm{t}-1}^{2}+\psi \text { logVolume } \mathrm{t}_{\mathrm{t}-1}
\end{aligned}
$$

where: $\alpha 1=\mathrm{ARCH}$ coefficient; $\beta 1=$ GARCH coefficient; $\gamma 1=$ asymmetric coefficient, i.e., coefficient of the asymmetric term; $\psi=$ augmentation coefficient, i.e., coefficient of trading volume in the conditional variance equation 
The a priori expectations are as follows:

$\alpha 1>0 ; \beta 1>0 ; \gamma 1<,>0$ for EGARCH and TGARCH respectively; $\psi<,>0 ; \alpha 1+\beta 1>1$ (to achieve covariance stationarity);

The rationale for $\psi<,>0$ is based on the fact that trading volume has yet an imprecise role in financial research (see Rose 1987). Nonetheless Lamoureux and Lastrapes (1990: 4) and Tiang and Guo (2006:12) assumed $\psi>0 . \alpha 1$ is expected to be positively related to $\log$ conditional variance (volatility) since past residuals increase current volatilities. Further, a priori, $\beta 1>0$ since past variances typically lead to higher contemporaneous volatilities. This is a prominent stylized fact of financial time series, the so-called volatility clustering.

As has been noted, equations $11,12,13,14,15$, and 16 are estimated, each, in three alternative error distributions: Guassian (normal), student's $t$ and generalized error distribution - giving rise to 18 equations. The results are as presented in Table 1.

\subsection{Data Source, Transformation and Test Procedure}

This study makes use of daily stock returns and trading volume of all listed companies in the Nigerian Stock Exchange. The data set were retrieved from cashcraft database (see www.cashcraft.com). Due to significant changes in the level of prices from time to time, it is more appropriate to base volatility measures on percentage return rather than absolute price movements. From investment point of view too, it is obvious that comparing rate of return is more meaningful than comparing absolute price movements (Rahman, Shafiqur, Lee, Cheng-Few and Ang, 2002, Tiang and Guo, 2006). The daily stock prices were logged (to reduce their variances) before transforming it to stock returns.

The daily stock return data set is calculated from daily stock price series by the formula:

$\mathrm{SRETt}=\ln (\mathrm{STOCKPt} / \mathrm{STOCKPt}-1 * 100)$

or SRET $=$ dlogSTOCKP $* 100$;

where $\ln =$ natural $\log ; \mathrm{d}=$ first difference operator,

$\mathrm{SRETt}=$ stock returns at time $\mathrm{t}, \mathrm{STOCKPt}=$ stock price at time $\mathrm{t}$.

The ASI used in this study spans from January 4, 2012 to 13th August , 2015 totaling 943data point for a '5-day per week' daily data set, out of which 913data points (January 4, 2012 to July2 , 2015) are used for model estimation and the remaining 30 data points (July 32015 to August 13, 2015) are used for model validation. This is important for optimal model selection. We also make use of its natural $\log$ of lagged trading volume series (logVolumet- 1$)$. The rationale for the use of log of lagged volume rather than its absolute lagged volume (as in Tian and Guo, 2006) is to improve the normality (standardize the variable) and, hence, better fit the GARCH-family models. The use of lag of volume (as suggested by Lamoureux and Lastrapes, 1990) rather than contemporaneous trading volume serves only to avoid possible simultaneity bias in that volume may not be strictly exogenous to stock returns.

\subsection{Model Selection/Forecasting Evaluation}

We estimate each of the volatility models - GARCH $(1,1)$, EGARCH $(1,1)$, TGARCH $(1,1)$ - and their augmented versions ((augmented GARCH $(1,1)$, augmented EGARCH $(1,1)$ andaugmented TGARCH $(1,1)$ ) in normal, student's $t$ and generalized error distribution (GED). This process generates eighteen volatility models. Model selection in terms of model fit was done using Schwarz information criterion (SIC). The model with least Schwarz criterion is adjudged the best fitted.

Another way of evaluating the adequacy of asymmetric models is the ability to show the presence of leverage effect; i.e., that bad news (negative shock) drives volatility higher than good news (positive shock) of equal size. The presence of leverage effect among the asymmetric models is examined by testing the null hypothesis that the asymmetric coefficient, $\gamma=0$ at $5 \%$ level of significance. Rejection of the null hypothesis implies the presence of leverage effect. In other words, the sign and significance of the asymmetric coefficient $(\gamma)$ point to the presence or otherwise of leverage effect.

To test whether or not the augmented model out-performs the non-augmented model, we check if model augmentation reduces the persistence parameters $(\alpha 1+\beta 1)$ or not (see Tian and Guo, 2006). This is synonymous to test of whether or not model augmentation increases the size and significance of asymmetric coefficient $(\gamma)$ and/or improved its sign - since decline in persistence parameter tends to be associated with the former 
In term of forecasting performance (predictive power), clement (2005) maintains that out-of-sample forecasting ability remains the best criterion for selecting the model with best predictive power. We rely on two out-of-sample model selection criteria, namely: root mean square error (RMSE) and Thiel's Inequality coefficient (TIC), U. The models with minimum root mean square error (RMSE) and Thiel's Inequality coefficient (TIC) are selected and adjudged to have the best predictive power.

\section{Results}

\subsection{Descriptive Statistics of Series}

We begin the presentation of our empirical findings by first reporting some descriptive statistics (stylized facts) of stock returns and the result of our test for ARCH effect which justifies the use of symmetric and asymmetric GARCH-family models for our analysis. Both the Augmented Dickey Fuller (ADF) and Philip Perron (PP) tests of a unit root indicate that trading volume and return series are stationary at level; hence, there is no fear of spurious regression (see Table 9 in Appendix 1). Two important statistics when examining financial time series are the kurtosis and skewness. Table 1reveals negative mean daily stock returns of -2.01 and the standard deviation which measures the riskiness of the underlying assets is 261.4. The higher the standard deviation, the higher the volatility of the market and the riskier the equity traded. Thus, this high volatility indicates high riskness of investing in the Nigerian stock exchange over the period under review. The difference between the minimum and maximum value of stock returns show wide variability in equity traded in the Nigerian stock exchange.

Table1. Descriptive statistic of Daily All-Shares Stock Returns
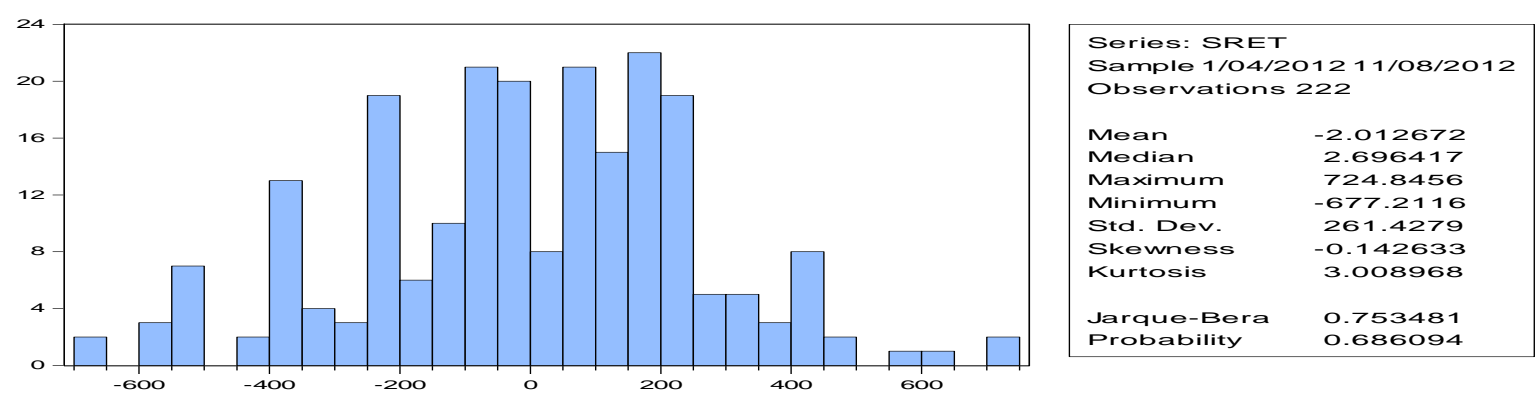

Source: Author

Again, considering the skewness (-0.142) which is less than 0 (skewness of a normal distribution is 0 ), it means that the rate of return is not symmetric. The negative skewness indicates higher probability of making losses (negative returns)from the Nigeria Stock Exchange. The kurtosis is 3.01 which is slightly greater than 3 (kurtosis of a normal distribution is 3). This indicates some degree of fattailcharacteristics although the Jarque-Bera statistics indicate that the series is close to being normality distributed.

The graphical test of volatility clustering (Figure 1) clearly shows that period of high volatility is accompanied by periods of low volatility. This feature of sustained period of high volatility and period of low volatility signifies volatility clustering, a stylized fact financial time series often exhibit. Our finding of volatility clustering and other stylized facts give credence to the application of GARCH-family models.

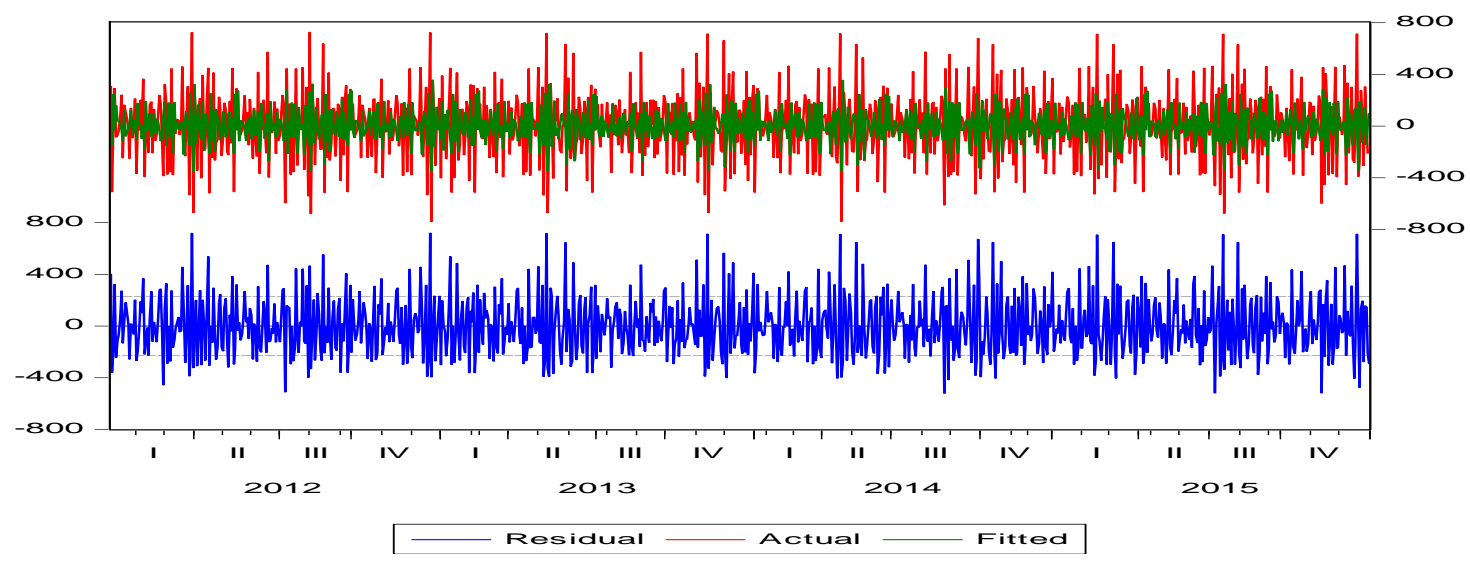

Figure1. Graph of Actual and Fitted values of Stock Returns 
As has been noted, the basic test for justification (or otherwise) for the application of GARCH-family model is the ARCH-LM test. Table 2 shows the result of the test for ARCH effect when the residual of the ARCH model is subjected to ARCH-LM test. Since the probability of $0.0003(0.03 \%)$ is less than 5\%, it implies that the test statistic falls inside the region of rejection of $\mathrm{HO}$. We, therefore, reject the null hypothesis (H0) of no ARCH effect. That is, we conclude that there is ARCH effect. This justifies the application of GARCH-family models for our analysis (see Atoi 2014; Tian and Guo, 2006; Chang, 2010; Jiang, 2012 for further expositions).

Table2. ARCH LM Test

\begin{tabular}{|c|c|c|c|}
\hline \multicolumn{2}{|c|}{ Heteroskedasticity Test: ARCH } & & \\
\hline F-statistic & 0.500613 & Prob. F(1,918) & $\mathbf{0 . 0 0 0 3}$ \\
\hline Obs*R-squared & 0.501431 & Prob. Chi-Square(1) & 0.0009 \\
\hline
\end{tabular}

Source: Author

\subsection{Model Selection}

The presence of ARCH effect with other established stylized facts (e.g. the presence of volatility clustering and negative skewness) gave credence to the estimation of GARCH-family models. The estimation is implemented in three error distributions with a view to establishing the best forecasting model. Table 3 presents the result of six volatility models $[(\operatorname{GARCH}(1,1), \operatorname{EGARCH}(1,1)$, TGARCH(1,1), Augmented GARCH(1,1), Augmented EGARCH(1,1), Augmented TGARCH(1,1)], implemented in three error distributions (Gaussian or normal error distribution, student's t error distribution, and generalized error distribution), which gives rise to eighteen GARCH-family models.

Table3. Estimation Results of GARCH-Family Models and their Augmented Versions

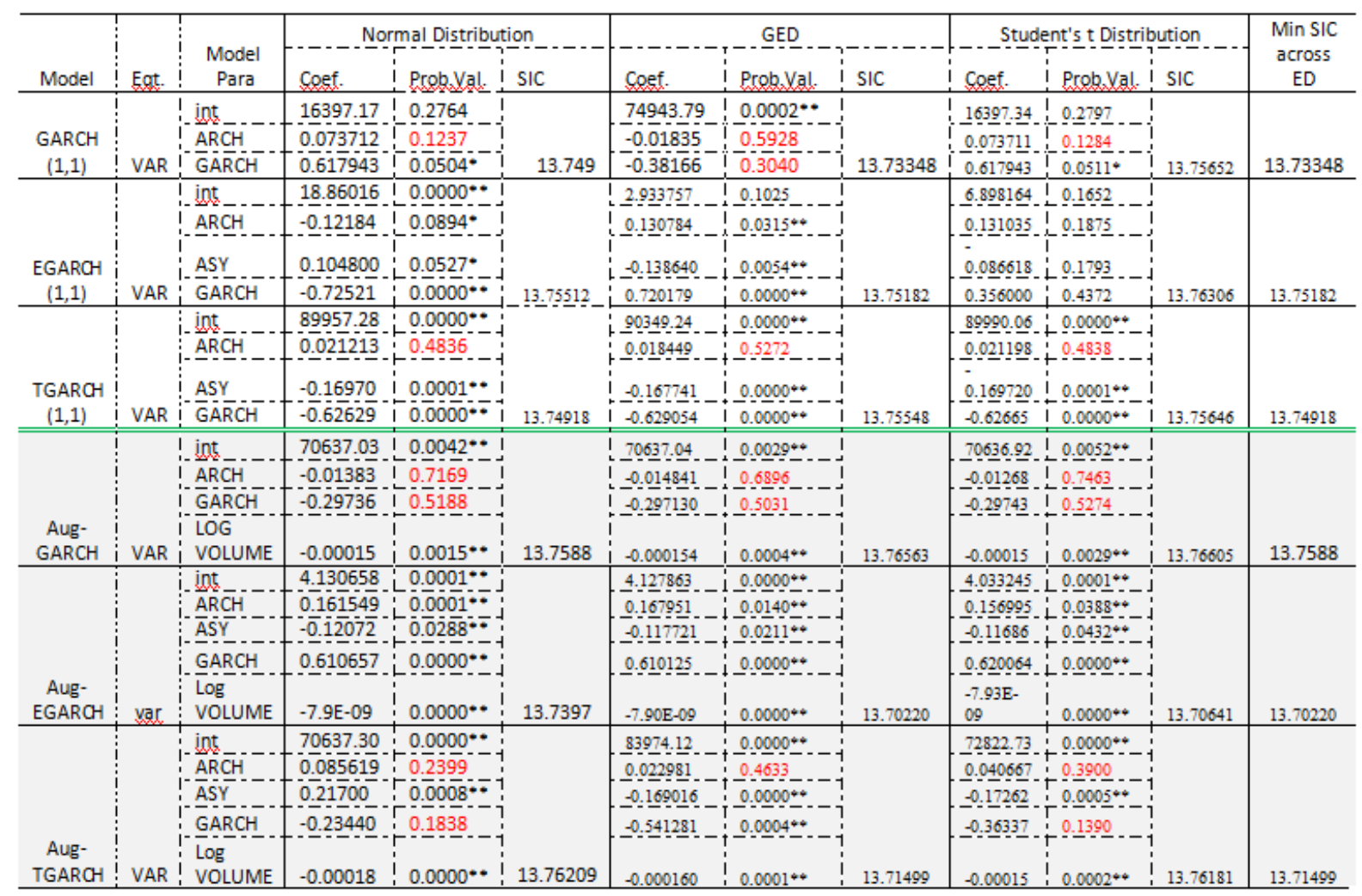

Source: Author; Note: ** means significant at 5\%

In terms of the standard (non-augmented) GARCH -family models, GARCH $(1,1)$ and EGARCH $(1$, 1) in GED, and TGARCH $(1,1)$ in normal error distribution returned least SIC. As regards the augmented asymmetric GARCH family models, the A_EGARCH $(1,1)$ in GED and A_TGARCH $(1,1)$ in GED returned minimum SIC. On the basis of these findings, $\operatorname{GARCH}(1,1), \operatorname{EGARCH}(1,1)$, A_EGARCH $(1,1)$, A_TGARCH $(1,1)$ in generalized error distribution and TGARCH $(1,1)$ in normal error distribution are selected for forecast performance evaluation with a view to determining the model with best forecasting capability. The results of the fore casting performance evaluation will 
not only supply lessons for optimal monetary policy intervention, it will also guide investor's choice of asset portfolio that ensures maximum profitability.

For clarity, the estimation results are presented in Table 4in abridged forms in what follows. The percentage improvement in fitness of model due to the augmentation of the model is shown in Table 4. As is obvious from the table 4, the inclusion of trading volume as a surrogate for information variable to explain volatility of stock returns (that is widely suggested in the literature) improved the fitness of the model. This is clearly shown by the relative minimum SIC for augmented GARCHfamily model (13.70220) with respect to its non-augmented counterpart (13.73348).

Table4. Model Fit and Improvement of Non-Gaussian Process over Gaussian Process

\begin{tabular}{|c|c|c|c|c|c|c|}
\hline \multirow[t]{2}{*}{$\begin{array}{l}\text { First Order } \\
\text { GARCH Models }\end{array}$} & \multicolumn{3}{|c|}{ Swartz information Criterion (SIC) } & \multicolumn{2}{|c|}{$\begin{array}{l}\text { \% improvementof } \\
\text { GaussianProcessby }\end{array}$} & \\
\hline & Normal Distribution & Student- $\mathrm{t}$ & GED & Student-t & GED & $\begin{array}{l}\text { Grand } \\
\text { Minimum SIC }\end{array}$ \\
\hline GARCH $(1,1)$ & 13.749 & 13.75652 & 13.73348 & 0.752 & 1.552 & 13.73348 \\
\hline$\overline{\mathrm{EGARCH}}(1,1)$ & 13.75512 & 13.76306 & 13.75182 & 0.794 & 1.124 & \\
\hline $\operatorname{TGARCH}(1,1)$ & 13.74918 & 13.75646 & 13.75548 & $\mathrm{NI}$ & $\mathrm{NI}$ & \\
\hline A_GARCH $(1,1)$ & 13.7588 & 13.76605 & 13.76563 & NI & NI & \\
\hline A_EGARCH $(1,1)$ & 13.7397 & 13.70641 & 13.70220 & 3.329 & 3.75 & 13.70220 \\
\hline A_TGARCH $(1,1)$ & 13.76209 & 13.76181 & 13.71499 & 0.028 & 4.682 & \\
\hline
\end{tabular}

\section{Source: Authors calculation}

'NI' Stands for Negative Improvement. This implies that TGARCH $(1,1)$ and augmented GARCH $(1,1)$ performed better under normal error distribution than under non-Gaussian process. 'A_' is a prefix for augmentation.

From the result in Table 4, the result of EGARCH $(1,1)$ cum lagged log-volume model performed better than other augmented models in terms of model fit. Similarly, as regards standard GARCHfamily models, GARCH $(1,1)$ outperformed other models. This later result is similar to that of Tian and Guo (2006:8) for China. In term of theoretical expectations, the augmentation coefficient $(\psi)$ in the EGARCH $(1,1)$ cum lagged log-volume model met the a priori expectations under the three alternative error distributions. This points to the importance of trade volume in explaining stock returns volatility and re-establishes the appropriateness of the A_EGARCH that has been selected (on the basis of minimum Scwartz information criterion) for forecast performance evaluation.

Next, we analyze the presence or otherwise of leverage effect. The asymmetric coefficient of EGARCH model $(\gamma 1)$ met the a priori expectation in generalized error distribution but failed to meet the right sign in normal and student's-t error distribution (see Table 5).

Table5. Analysis of Leverage Effect in asymmetric GARCH-family Models

\begin{tabular}{|l|l|l|l|}
\hline \multirow{2}{*}{ Asymmetric GARCH-family Model } & \multicolumn{3}{|l|}{ Asymmetric GARCH Coefficients $\left(\gamma_{\mathrm{i}}\right)$ Under Alternative Error Distributions } \\
\cline { 2 - 5 } & Normal & Student's t & GED \\
\hline EGARCH $(1,1)$ & $0.1048\left(0.0527^{* *}\right)$ & $0.086618(0.1793)$ & $\mathbf{- 0 . 1 3 8 6 4}\left(0.0054^{* *}\right)$ \\
\hline TGARCH $(1,1)$ & $-0.1697\left(0.0001^{* *}\right)$ & $\mathbf{0 . 1 6 9 7 2}\left(0.0001^{* *}\right)$ & $-0.16774\left(0.000^{* *}\right)$ \\
\hline A_EGARCH $(1,1)$ & $-\mathbf{0 . 1 6 1 5 5}\left(0.0001^{* *}\right)$ & $\mathbf{- 0 . 1 1 6 8 6}\left(0.0432^{* *}\right)$ & $\mathbf{- 0 . 1 1 7 7 2}\left(0.0211^{* *}\right)$ \\
\hline A_TGARCH $(1,1)$ & $\mathbf{0 . 2 1 7}(0.0008)$ & $-0.1726\left(0.0005^{* *}\right)$ & $-0.16902\left(0.000^{* *}\right)$ \\
\hline
\end{tabular}

Source: Author

Note: The values in parenthesis the t-statistics. ** indicates significance at $5 \%$ level of significance.

As Table 5clearly shows, the asymmetric coefficients ( $\gamma \mathrm{i})$ across the three error distribution are significantly (statistically) different from zero showing the preponderance of leverage effect in Nigeria's stock returns. Thus, we conclude that the asymmetric GARCH-family models (and their augmented versions) indicate the presence of leverage effect. This means that bad news tend to induce higher volatility in stock returns than good news of equal magnitude. But as Table 5 also shows, the augmented EGARCH model shows more consistence in terms of signs of the asymmetric parameter 
( $\gamma \mathrm{i})$ across the three error distribution than its sister models. This result is not surprising given the fact that the A_EGARCH also returned least SIC among all augmented asymmetric GARCH models - on the basis of which it was selected as the best fitted asymmetric GARCH-family model analyzed in the study.

Further, to investigate whether or not augmented models out-performs non-augmented models, we examine if model augmentation reduced persistence parameter $(\alpha 1+\beta 1)$ in line with theoretical explanations (see Lamoureux and Lastrapes, 1990 and Tian and Guo, 2006 for an exposition).

Table6. Change in Persistent Parameter $(\alpha 1+\beta 1)$ after Augmentation (\%)

\begin{tabular}{|c|c|c|c|c|c|c|c|c|c|c|}
\hline \multicolumn{4}{|c|}{$\begin{array}{l}\text { Persistence Parameter before } \\
\text { Augmentation }\end{array}$} & \multicolumn{4}{|c|}{$\begin{array}{l}\text { Persistence Parameter after } \\
\text { Augmentation }\end{array}$} & \multicolumn{3}{|c|}{$\begin{array}{l}\% \text { improvement (Decrease in } \\
\text { Absolute Terms) } \\
\text { in Persistent Parameter }\left(\alpha_{1}+\right. \\
\left.\beta_{1}\right) \text { due to Augmentation }\end{array}$} \\
\hline $\begin{array}{l}\text { Model } \\
\text { Type }\end{array}$ & $\begin{array}{l}\text { Normal } \\
\text { Distribution }\end{array}$ & Student-t & GED & Model Type & $\begin{array}{l}\text { Normal } \\
\text { Distribution }\end{array}$ & Student-t & GED & $\begin{array}{l}\text { Normal } \\
\text { Distribution }\end{array}$ & Student's-t & GED \\
\hline \begin{tabular}{|l|} 
GARCH \\
$(1,1)$
\end{tabular} & 0.691655 & 0.69165 & $\begin{array}{l}0.400 \\
01\end{array}$ & AGARCH & 0.31119 & 0.31011 & 0.311971 & 38.1 & 38.15 & 8.8 \\
\hline $\begin{array}{l}\text { EGARCH } \\
(1,1) \\
\end{array}$ & {$[0.84705$} & 0.48704 & $\begin{array}{l}0.850 \\
96 \\
\end{array}$ & AEGARCH & 0.772206 & 0.777059 & 0.778076 & 7.48 & -29 & 7.2 \\
\hline $\begin{array}{l}\text { TGARCH } \\
(1,1)\end{array}$ & 0.647503 & 0.64785 & $\begin{array}{l}0.647 \\
50\end{array}$ & ATGARCH & 0.320019 & 0.40403 & 0.56426 & 32.75 & 24.38 & 8.3 \\
\hline
\end{tabular}

Source: Author

As can be seen from the Table6, except for EGARCH $(1,1)$ model under student's t error distribution assumption, the augmentation of all GARCH-family models with log of lagged trade volume led to decrease in persistent parameters $(\alpha 1+\beta 1)$.In other words, model augmentation increased leverage effect (represented by the coefficient, $\gamma$ )in stock returns.

Evaluating the empirical merit of whether or not trade volume explains stock returns volatility, Table 7 shows that the coefficients of lagged log volume in the conditional variance (volatility) equations of all augmented GARCH-family model met the theoretical a priori expectation in that they are all negatively related to volatility. The coefficients of log lagged trade volume $(\psi)$ are highly significant under the three alternative error distribution assumptions. This implies that trade volume plays quite a significant role (as a surrogate for information arrival) in explaining stock returns volatility in Nigeria. This result is similar to Lamoureux and Lastrapes (1990) but differ from those of Najand and Yung (1991) and Foster (1995).

Table7. Relative Importance of Trade Volume in Augmented GARCH-family Models

\begin{tabular}{|l|l|l|l|}
\hline \multicolumn{3}{|l|}{ Coefficients of lagged log-volume in augmented GARCH family model $\left(\psi_{\mathrm{i}}\right)$ in three Error Distributions } \\
\hline & Normal & Student's t & GED \\
\hline A_GARCH & $-0.000154\left(0.0015^{* *}\right)$ & $-0.00015(0.0029 * *)$ & $-0.000154(0.0004 * *)$ \\
\hline A_EGARCH & $-7.9 \mathrm{E} 109\left(0.000^{* *}\right)$ & $-7.93 \mathrm{E} 109\left(0.000^{* *}\right)$ & $-7.9 \mathrm{E} 9\left(0.000^{* *}\right)$ \\
\hline A_TGARCH & $-0.00018\left(0.000^{* *}\right)$ & $-0.00015\left(0.0002^{* *}\right)$ & $-0.00016(0.0001 * *)$ \\
\hline
\end{tabular}

Note: The Values in parenthesis are the probability values. $* *$ indicates significance at $5 \%$ level of significance Evidence from the foregoing analyses have led to the selection of five volatility model $\operatorname{GARCH}(1,1)$, EGARCH(1,1), A_EGARCH(1,1), A_TGARCH $(1,1)$, and TGARCH $(1,1)$-based on minimum SIC for evaluation of forecast performance. The result also shows that, in general, the volatility models performed better in generalized error distribution (GED) than in normal and student's t error distributions. So far, we also found evidence of volatility clustering, leverage effect and the fact that trading volume plays quite a significant role in explaining stock returns volatility in Nigeria. Since we are essentially interested in determining the optimal forecasting model of stock returns in Nigeria, we analyze the forecast-performance of the five best-fitted GARCH-family models earlier selected on the basis of minimum SIC.

As Table 8 clearly shows, GARCH $(1,1)$ in GED out-performed other GARCH-family models as it returned minimum RMSE and Thiel's Inequality Coefficient (264.45 and 0.6086), respectively. As regards the augmented models, A_EGARCH $(1,1)$ model in GED proved to be the best performing model.

Table8. Forecast-Performance Evaluation of Five Best-Fitted GARCH-family Model 


\begin{tabular}{|c|c|c|c|c|c|}
\hline \multicolumn{6}{|c|}{ Selected GARCH-family Models } \\
\hline \multirow{2}{*}{$\begin{array}{l}\text { Evaluation } \\
\text { Criteria }\end{array}$} & \multicolumn{4}{|c|}{ In Generalized Error Distribution (GED) } & in Normal Error \\
\hline & $\operatorname{GARCH}(1,1)$ & EGARCH $(1,1)$ & A_EGARCH $(1,1)$ & A_TGARCH $(1,1)$ & TGARCH $(1,1)$ \\
\hline RMSE & 264.45 & 264.47 & 264.9215 & 261.6744 & 261.7491 \\
\hline TIC(U) & 0.6086 & 0.60155 & 0.59992 & 0.635165 & 0.6295 \\
\hline $\begin{array}{l}\text { Bias } \\
\text { Proportion }\end{array}$ & 0.0071 & 0.00047 & 0.00158 & 0.001656 & 0.0004 \\
\hline $\begin{array}{l}\text { Variance } \\
\text { Proportion }\end{array}$ & 0.2627 & 0.23991 & 0.2322 & 0.3613 & 0.3434 \\
\hline
\end{tabular}

Source: Author (see EViews' direct Output in Appendix)

Note: $0=>U=<1$ : there is Perfect Fit if $U=0$; there is Worse Fitif $U=1$

Lower root mean square error (RMSE) indicates better forecasting ability of a model.

The result of forecasting performance evaluation is further buttressed by graph of 30-day out-ofsample forecast evaluation (Figure 2). Figure 2 presents five panels (A, B, C, D, E) indicating graphs of daily actual/forecast of stock returns plotted against time. A perceptive review of figure 2 indicates that the forecast of stock returns in panels $\mathrm{A}$ and $\mathrm{C}$ more closely trails actual returns than those of panels B, D and E.
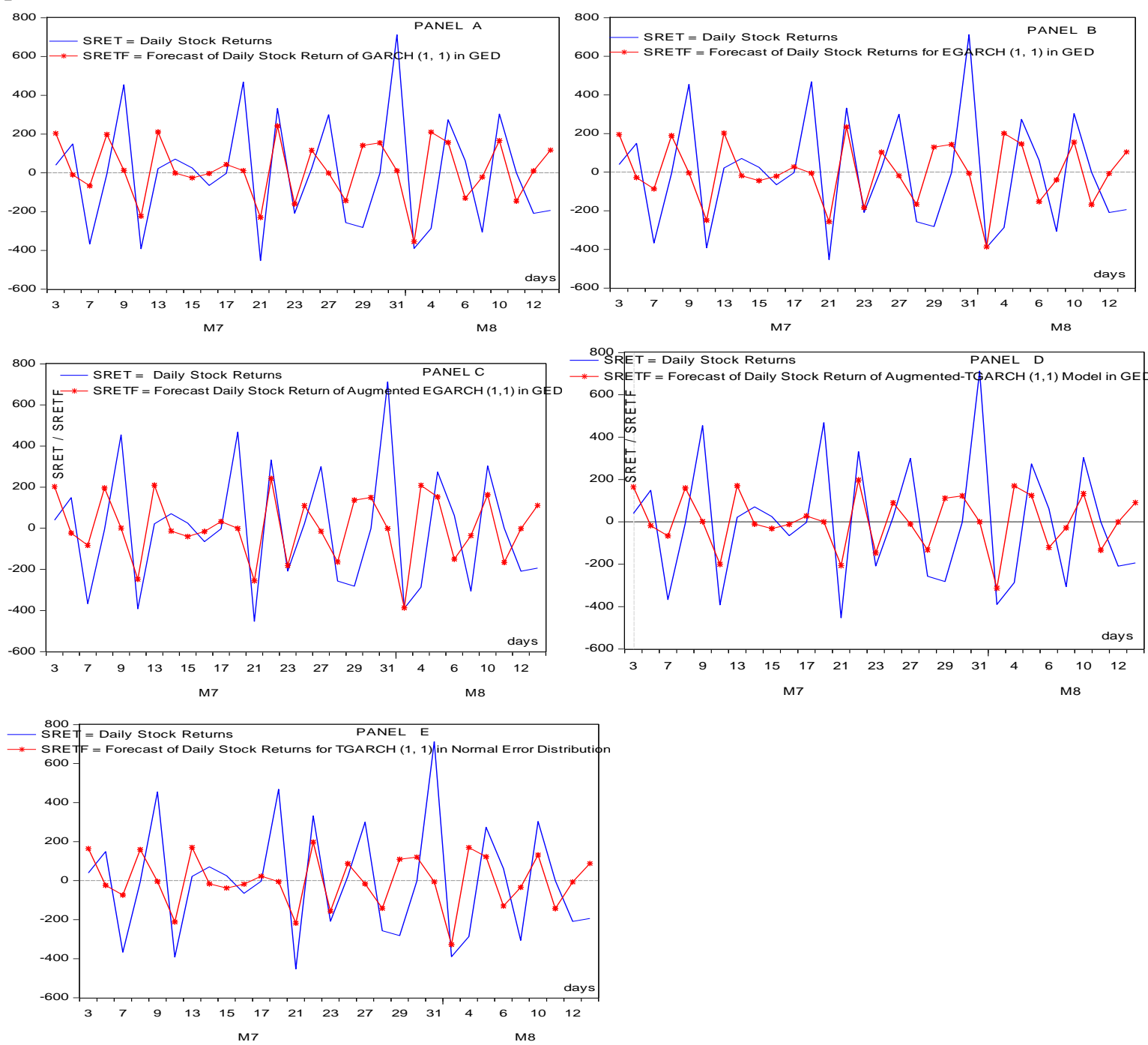

Figure2. Actual/Forecast of Returns for Best-Fitted GARCH-family Model in Alternative Error Distributions (July 3, 2015 to August 13, 2015)

Source: Author (see actual and forecast data on daily stock returns in appendix)

Therefore, on the basis of minimum RMSE and Thiel's Inequality coefficient, GARCH $(1,1)$ and A_EGARCH $(1,1)$ in generalized error distribution are adjusted the best performing GARCH-family model for analyzing Nigerian stock returns.

\section{APPENDIX 1}


Application of Garch Models to Estimate and Predict Financial Volatility of Daily Stock Returns in Nigeria

Table9. Result of Unit Root Test

\begin{tabular}{|c|c|c|c|c|c|c|c|}
\hline VAR & \multicolumn{3}{|c|}{ ADF Statistics } & \multicolumn{3}{|c|}{ PP statistics } & \multirow[b]{2}{*}{ Final conclusion } \\
\hline & Lev & 1st Diff & Conclu & Lev & 1st Diff & Conclu & \\
\hline STOCKP & 1.72 & -1.12 & inc & $4.96^{*}$ & -1.56 & $\mathrm{I}(0)$ & $\mathrm{I}(0)$ \\
\hline SRET & -48.93 & - & $\mathrm{I}(0)$ & 5282.2 & - & $\mathrm{I}(0)$ & $\mathrm{I}(0)$ \\
\hline Volume & -280.75 & - & $\mathrm{I}(0)$ & -282.02 & - & $\mathrm{I}(0)$ & $\mathrm{I}(0)$ \\
\hline
\end{tabular}

Source: Author's computation.

Note: 'Drift' or 'intercept' is assumed across the battery of Unit Root Tests; the respective critical values (CV) are ADF (2.93), and PP (2.93). * indicates significance at 5\% LOS. The variables were examined in their level form, taking cognizance of the fact that taking log of variable is one way of inducing stationarity in data. The critical values changes when we assume 'Drift' 'Drift and Trend' or 'none'. Inc stands for inconclusive.

\section{CONCLUSION AND RECOMMENDATIONS}

Our results shows that, in general, the volatility models performed better in generalized error distribution (GED) than in normal and student's t error distributions. We found evidence of volatility clustering, leverage effect and the fact that trading volume plays quite a significant role in explaining stock returns volatility in Nigeria. As regards the augmented models, EGARCH $(1,1)$ model in GED proved to be the best performing model. On the basis of minimum RMSE and Thiel's Inequality coefficient, GARCH $(1,1)$ and A_EGARCH $(1,1)$ in GED are adjusted the best performing GARCHfamily model for analyzing Nigerian stock returns. Overall, the result provides evidence of high probability of making negative return from investment in the Nigerian stock market over the sample period. We recommend that alternative error distributions should be considering when modeling stock returns so as to guarantee robust volatility forecasting model for sound policy decision and proper investment portfolio choice

\section{REFERENCES}

[1] Atoi, N. V. (2014). Testing Volatility in Nigeria Stock Market Using GARCH Models. Central Bank of Nigeria Journal of Applied Statistics, 5, 2, 65-93.

[2] Anders, W. (2006). GARCH Fore casting performance under different assumptions. Journal of Forecasting 25, 561-578.

[3] Black, F. (1976). Studies in stock price volatility changes. In Proceedings of the 1976 Business Meeting of the Business and Economics Statistics Section, American Statistical Association (pp. 177-181).

[4] Bollerslev, T. (1986). Generalized Autoregressive Conditional Heteroskedasticity. Journal of Econometrics, 31 (3): 307-327. doi:10.1016/0304-4076(86)90063-1.

[5] Bollerslev, T. and Domowitz, I. (1991) Price volatility, spread variability and the role of alternative market mechanisms, The Review of Future Markets, 10(1), 78-102.

[6] Chang, S. (2010). Application of EGARCH Model to Estmate Financial Volatility of Daily Returns: The Empirical Case of China. School of Business, Economics and Law, University of Gothenburg.

[7] Clark, P. K. (1973) A subordinated stochastic process model with finite variance for speculative prices, Econometrica, 41, 135-156.

[8] Clements, M.P. (2005). Evaluating Econometric Forecasts of Econometric and Financial Variables. Palgrave Texts in Econometrics, Palgrave Macmillian, Houndmills, UK.

[9] Copeland, T. (1976). A Model of Asset Trading under the Assumption of Sequential Information Arrival." Journal of Finance 31, 1149-1168.

[10] Dallah, H. and Ade I. (2010). Modelling and Forecasting the Volatility of the Daily Returns of Nigerian Insurance Stocks. International Business Research 3(2):106-116.

[11] Diebold, F. and Nerlove, M. (1989) The dynamics of exchange rate volatility: a multivariate latent factor ARCH model, Journal of Applied Econometrics, 4(1), 1-22.

[12] Ding, Z., Granger, C W. J. and Engle, R. F. (1993). A Long Memory Property of Stock Market Returns and a New Model. Journal of Empirical Finance, 1:83-106. 
[13] Engle, R. F. (1982). Autoregressive Conditional Heteroscedasticity with Estimates of Variance of United Kingdom Inflation. Econometrica, 50 (4): 987-1008.

[14] Engle, R.F., Focardi, S.M., \& Fabozzi, F.J. (2007). ARCH/GARCH Models in Applied Financial Econometrics. JWPR-026.

[15] Epps, T. and Epps, E. (1976) "The Stochastic Dependence of Security Price Changes and Transaction Volumes: Implications for the Mixture of Distributions Hypothesis." Econometrica 44, 305-32.

[16] Eric, Z. (2008). Practical Issues in the Analysis of Univariate GARCH Models. Handbook of Financial Statistics, Springer-Verlag.

[17] Fama, F.E. (1965). The Behaviour of Stock Prices. Journal of Business 38(1):34-105.

[18] Fischer, S. (1981). Relative stocks, relative price variability, and inflation. Brookings paper on economic activity 2:111-137.

[19] Foster, A., (1995) Volume-Volatility Relationships for Crude Oil Futures Markets. Journal of Futures Markets 15, 929-951.

[20] Franses, P. H. and McAleer, M. (2002). "Financial Volatility: An Introduction", Journal of Applied Econometrics, 17:419-424.

[21] Glosten, L. R., Jagannathan, R. and Runkle, D. E. (1993). On the Relation between the Expected Value and the Volatility of the Nominal ExcessReturn on Stocks. Journal of Finance, 48(5):1779-1801.

[22] Harvey, A. \& Chakravarty, T. (2008). Beta-t-(E) GARCH: Cambridge University Working Papers in EconomicsACH34@ECON.CAM.AC.UK.

[23] Harvey, A. \& Sucarrat, G. (2012). EGARCH Models with fat tails, Skewness and Leverage. Cambridge University Working Papers in Economics, ACH34@ECON.CAM.AC.UK.

[24] Jayasuriya, S. (2002). Does Stock Market Libralisation Affect the Volatility of Stock Returns?: Evidence from Emerging Market Economies. Georgetown University Discussion Series.

[25] Jiang, W. (2012). Using the GARCH Model to Analyze and Predict the different Stock Markets. An M.Sc. Dissertation, Department of Economics, Uppsala University, Sweden.

[26] Lamoureux C.G., Lastrapes W.D. (1990) Heteroskedasticity in Stock Return Data: Volume versus GARCH Effects. Journal of Finance, 45, 221-229.

[27] Malmsten, H. and Terasvirta, T. (2004). Stylized facts of financial time series and three popular models of volatility, SSE/EFI Working Paper Series in Economic and Financial Finance 563, Stockholm School of Economics.

[28] Mandelbrot B. (1963). The Variation of Certain Speculative Prices. The Journal of Business, 36(4):394-419.

[29] Najand, M. and K. Yung (1991) A GARCH Examination of the Relationship between Volume and Price Variability in Futures Markets. Journal of Futures Markets 11, 613-621

[30] Nelson, D. B. (1991). "Conditional Heteroskedasticity in Asset Returns: A New Approach", Econometrica, 59(2):347-370. JSTOR 2938260.

[31] Ogum, G. Beer, F and Nouyrigat, G. (2005). Emerging Equity Market Volatility: An Empirical Investigation of Markets in Kenya and Nigeria. Journal of African Business 6 (1/2):139-154.

[32] Okpara, G. C. and Nwezeaku, N. C. (2009). Idiosyncratic Risk and the Crosss-Section of Expected Stock Returns: Evidence from Nigeria. European Journal of Economics, Finance and Administrative Science, 17:1-10.

[33] Rahman, Shafiqur, Lee, Cheng-Few and Ang K. P. (2002) Intraday return volatility process: evidence from NASDAQ stocks. Review of Quantitative Finance and Accounting, 19: 155-180.

[34] Rydberg, T. H. (2000). Realistic statistical modelling of financial data. International Statistical Review, 68(3):233-258.

[35] Schwert, G. W. (1989). Why does market volatility change over time? Journal of Finance, 44:1115-1153.

[36] Spiro, P. S. (1990). Stock market overreaction to bad news in good times: A rational expectation equilibrium model. Review of Financial Studies 12:975-1007. 
[37] Taylor, S. (1986), Modelling Financial Time Series, Wiley, Chichester.

[38] Tian, G., \& Guo, M. (2006). Intraday Return, Volatility and Liquidity: An investigation of the Market Microstructure of the Chinese Stock Exchange. An unpublished Ph.d Thesis submitted to the school of Economics and Finance, University of Western Sydney, May 2006.

[39] Http//:www.cashcraft.com

[40] Zakoian, J. M (1994). "Threshold Heteroskedasticity Models". Journal of Economic Dynamics and Control, 18:931-955.

\section{AUTHORS' BIOGRAPHY}

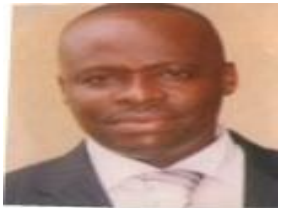

Chrispher N. Ekong is Professor of Economics at the University of Uyo, Nigeria. $\mathrm{He}$ is a John F. Kennedy Scholar on 'Leading Economic Growth' at John Kennedy School, University of Harvard.

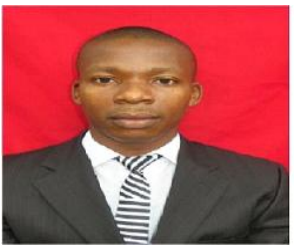

Kenneth U. Onye received his Ph.D in Monetary Economics from the University of Uyo, Nigeria were he currently teachers.

Citation: Christopher N, Ekong, and Onye Kenneth U. "Application of Garch Models to Estimate and Predict Financial Volatility of Daily Stock Returns In Nigeria." International Journal of Managerial Studies and Research (IJMSR), vol 5, no. 8, 2017, pp. 18-34. doi:http://dx.doi.org/10.20431/2349-0349.0508003

Copyright: (C) 2017 Authors. This is an open-access article distributed under the terms of the Creative Commons Attribution License, which permits unrestricted use, distribution, and reproduction in any medium, provided the original author and source are credited. 